\title{
ROSALIA: эффективность и безопасность комбинированной антигипертензивной и холестерин-снижающей терапии (лизиноприл-амлодипин и розувастатин) в популяциях пациентов высокого и очень высокого риска
}

\begin{abstract}
Сердечно-сосудистые заболевания (ССЗ) занимают первое место по смертности во всем мире, в частности в Венгрии. По прогнозам Всемирной организации здравоохранения (ВОЗ) в течение следующего 10-летнего периода сердечно-сосудистые заболевания будут по-прежнему ведущей причиной смерти [1]. Комбинированное применение ингибитора ангиотензинпревращающего фермента (ИАПФ) и блокатора кальциевых каналов длительного действия лизиноприл/ амлодипин (торговое название препарата - Экватор) выделяется среди комбинированных антигипертензивных стратегий лечения артериальной гипертензии наличием дополнительных свойств защиты органов-мишеней (уменьшение толщины интима-медиа сонной артерии и гипертрофии левого желудочка), которые могут быть продемонстрированы независимо от уровня артериального давления (АД) [3, 4].
\end{abstract}

Исследование множественных факторов риска MRFIT (Multiple Risk Factor Intervention Trial) в 1995 году показало, что сочетанное повышение систолического артериального Аавления и уровня общего холестерина приводит к значительному росту серАечнососудистой заболеваемости. С техпор многочисленные контромируемые рандомизированные клинические исслеАования с участием большого количества участников Аоказали, что проведение первичной и вторичной профилактики с применением Статинов привоАИт К СНижению КОличества СерАечно-СосУАИстых событий (4S, ^ипиАного, AFCAPS) [5-8]. С помощью тестов визуализации (IVUS - исслеАование коронарных артерий с использованием специального внутрисосуАистого Аатчика малого Аиаметра, СІМТ - ультрасонографическая оценка толщины интимымеАии сонной артерии) было также Аоказано, что при снижении более чем на 50\% по отношению К ИсхоАному Уровню холестерина ^ипопротеИАОв низкой плотности (АПНП) не только замеАляется рост атеросклеротических бляшек (исслеАование REVERSAL), но также наблюАается их регресс (исслеАование ASTEROID) [9, 10]. В протоколах Европейской ассоциации карАио^огов по ^ечению АислипиАемий (ESC/EAS 2011) и 5-й Венгерской консенсусной конференции по серАечно-сосУАИстой патологии рекоменАуется применение гиполипиАемической терапии АО Аостижения целевых уровней холестерина (ХC) АПНП. В случае высокого карАиоваскулярного риска целевое значение ХС $\wedge П Н П$ Аолжно быть <2,5 ммоль/^, а при очень высоком риске $<1,8$ ммоль/^ и/или снижение на $>50 \%$ от исхоАного уровня, если целевой уровень не может быть Аостигнут. Протокол Американской комеегии карАиологов/Американской ассоциации серАца (АСС/АНА), изАанныЙ в ноябре 2013 гоАа, привел к изменению параАигмы. Согласно рекоменАациям нового протокола было преАложено отказаться от целевых значений уровня

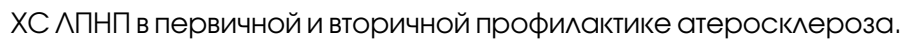
Эффективность гиполипиАемической терапии преАложено опреАелять по величине процентного снижения уровня ХС АПНП: среднеэффективное (снижение на 35-50\%) или высокоэффективное (снижение >50\%) в зависимости от выраженности серАечнососуАистого риска пациента.
Розувастатин (торговое название препарата - Мертенил) яв^яется оАНим Из наиболее эффективных и хорошо переносимых статинов. Применение этого препарата булет способствовать Аостижению значения целевого уровня ХС АПНП в контексте первичной и вторичной профилактики большинству пациентов (исслеАОвания STELLAR, MERCURY I) [11, 12]

В исслеАОвании ROSALIA провоАИ^ся анализ эффективности и безопасности комбинированной антигипертензивной терапии мизинопри^/ам^оАипин с фиксированной Аозой в сочетании с холестерин-снижающей терапией розувастатином у пациентов с ^егкой или умеренной артериальной гипертензией и гиперхо^естеринемией с высоким и очень высоким серАечно-сосудистым риском. Целью Аанного 6-месячного Клинического проспективного обсервационного неинвазивного исслеАования (номер этического разрешения: ЕTT TUKEВ 8096-1/2012/EKU) бы^о выявить, у какого количества пациентов, участвующих в исслеАовании по применению комбинированной терапии с фиксированной АОзой препаратов лизиноприл/амлоАипин (10мг/5 мг, 20 мг/5 мг, 20 мг/10 мг), эффективно снижается изначально повышенное артериальное Аавление Ао целевого уровня. Что касается липиАного профиля, было провеАено опреАеление количества пациентов, у которых ранее не был Аостигнут целевой уровень ХС АПНП в результате применения Аругих статинов, но в результате применения розувастатина (10 мг и 20 мг) Аанный уровень бы^ АОстигнут.

Вторичная цель состоит в том, чтобы оценить безопасность и переносимость оАновременной лизиноприл/амлоАипин и розувастатин терапии, неблагоприятные (побочные) эффекты, возникающие после начала терапии, частоту таких событий и процент побочных эффектов, приводивших к отмене терапии.

\section{Материалы и методы исследования}

\section{Отбор пациентов}

В исслеАование бы^о включено 2452 пациента с легкой и умеренной степенью артериальной гипертензии с высоким И очень ВЫСОКИм СерАечно-СОСУАИСтЫМ РИСКОМ. ИсСлеАОвание провоАилось в 256 меАицинских центрах врачами общей прак- 
тики и специалистами карАиологами. Критерии включения в исследование:

- возраст старше 18 ^ет;

- мягкая (степень 1) или умеренная (степень 2) артериальная гипертензия (АГ) у пациентов, ранее не получавших антигипертензивную терапию, или при отсутствии эффективности проводившейся ранее терапии, которая не привела к Аостижению целевого уровня артериального Аавления: больные с высоким кардиоваскулярным риском и бессимптомной АГ при уровне АA $\geq 140 / 90$ мм рт.ст.; пациенты с сахарным Аиабетом, метаболическим синдромом, ишемической болезнью серАца и атеросклерозом артерий нижних конечностей при уровне $A \triangle \geq 130 / 80$ мм рт.ст.; пациенты с АГ в возрасте старше 79 лет при уровне АА $\geq 150 / 90$ мм рт.ст;

- гиперхолестеринемия, уровень ХС АПНП выше целевого уровня, определение которого основывалось на серлечнососУАИстом риске: в случае отсУтствия Симптомов поражения СерАечно-сосУАИстой системы и высоком серАечно-

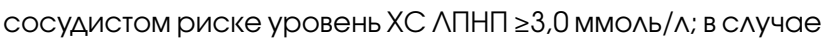
высокого серАечно-сосуАистого риска (наличие сахарного Аиабета, метаболического синарома, ишемической болезни серАца и атеросклероза артерий нижних конечностей) уровень ХС $\wedge П Н П \geq 2,5$ ммоль/^; в группе очень высокого риска уровень ХС $\wedge П Н П \geq 1,8$ ммоль/^;

- ознакомление пациента с содержанием информационной брошюры и поАписание преАварительного заявления о согласии.

Пациенты не принимались в исследование, если имели противопоказания, перечисленные в инструкциях по применению лизиноприла, амлодипина и розувастатина; непереносимость ИАПФ, статинов, блокаторов кальциевых каналов.

КажАОму вкАюченному в 6-месячное исслеАование пациенту опреАеляли: СКорость Клубочковой фильтрации, креатинин в сыворотке крови, общий холестерин, ХС АПНП, ХС АПВП, триглицериды, уровни $\mathrm{Na}^{+}$и К + в сыворотке крови, С-реактивного протеина, печеночных трансаминаз (АсАТ и А^АТ), мочевой кислоты,

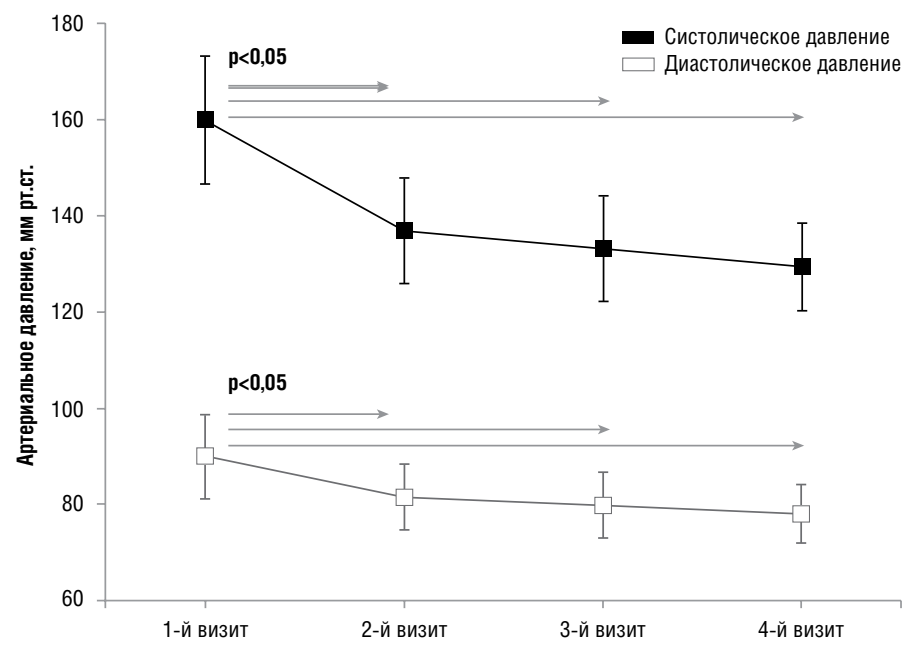

Рис. 1. Динамика снижения систолического и диастолического артериального давления на фоне лизиноприл/амлодипин терапии уровень микроальбуминурии. Проводили определение индекса массы тела, суточное мониторирование АА.

При повторных визитах (через 1, 3, 6 месяцев) были проведены повторные ^абораторные исследования (согласно общеприНятой метоАИке).

В исслеАОвании применялись слеАующие лекарственные среАства: ^изиноприл/амлоАипин (Экватор) в форме таблеток (10 мг/5 мг, 20 мг/5 мг, 20 мг/10 мг); розувастатин (Мертенил) в форме таблеток (10 мг, 20 мг).

МеАикаменты выАавались поА наблюАением меАицинского персонала.

Во время всех послеАующих посещений была возможность коррекции Аозы согласно критериям эффективности или переносимости соответствующих препаратов.

Аанные больных регистрировали в исследовательской форме на основе протокола.

Проводилась статистическая оценка полученных данных. Обработка полученных результатов осуществлялась в соответствии со станАартами EUGCP/ICH. Кроме обычных станАартных исследований (среАнее, SD, меАиана, Т-тест), статистический анализ клинических и лабораторных Аанных провоАили с помощью корреляционного и Аисперсионного анализа (95\% Аоверительный интерва^ межАУ начальным и конечным визитом) с АОстоверным уровнем вероятности $(p<0,05)$.

\section{Результаты и их обсуждение}

В общей сложности 2452 пациента были ввеАены в исслеАование, в конце исследования были обработаны в общей сложности данные 2241 пациента; в 211 случаях пациенты были исключены из-за несоблюАения протокола (преимущественно неполной АОкументации).

СреАний возраст пациентов состави^ 63,2 11,4 гоАа. На основе оценки риска, предложенной 5-й терапевтической консенсусной конференцией, в группу очень высокого кардиоваскулярного риска были отнесены 6,8\% больных (158 пациентов). Гипертоническая болезнь 1-й степени тяжести была выявлена у 48\% пациентов, 2-я степень - у 52\%. Ранее не получали антигипертензивную терапию 32\% пациентов, в то время как 68\% получали лекарственную терапию: 65\% монотерапию и 35\% - комбинированную.

\section{Влияние лизиноприл/ амлодипин терапии на артериальное давление}

Аинамика снижения систолического и Аиастолического АА на фоне приема комбинации лизиноприл/ам^оАипин показана на рисунке 1. По отношению к исхоАному визиту, ко 2-му визиту величины систолического и Аиастолического АА Аостоверно уменьшились. Как результат титрования Аозы лизинопри^/ам^оАипин уровень АА наиболее выражено был снижен к 6-му месяцу (4-й визит).

Снижение частоты сердечных сокращений было небольшим в клиническом смысле, но тем не менее Аостоверным к 6-му месяцу терапии, по сравнению с начальным значением (75,3 38,0 /

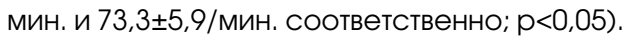


Пациенты, которые получали ранее гипотензивную терапию, реагировали аналогично пациентам, не получавшим ее, в плане снижения артериального Аавления.

\section{Применяемые дозы препарата лизиноприл/амлодипин}

Распределение Аозы таблетированного препарата лизиноприл/ам^оАиПин, использованного в Аанном исслеАовании (10 мг/5 мг, 20 мг/5 мг, 20 мг/10 мг), показано на рисунке 2.

\section{Эффективность лизиноприл/амлодипин терапии}

Авторы считали, что терапия ^изинопри^/ам^оАипин была эффективной, если АА было ниже целевого значения Аля группы риска. В результате титрования Аозы целевое значение АА $<140 / 90$ мм рт.ст. бы^о Аостигнуто у 68\% больных ко 2-му визиту иу 91\%-к 4-му визиту (рис. 3). Целевое значение АА < 130/80 мм рт.ст. было Аостигнуто у 30\% пациентов к моменту 2-го посещения и у 57\% - к 4-му визиту. Важно поАчеркнуть, что в 2013 году рекоменАациями по лечению артериальной гипертензии ЕSC/ESH, опубликованными во время провеАения исслеАования, был упразАненцелевой уровень АА < 130/80 мм рт.ст. Целевой уровень AА Аля пациентов старше 79 ^ет считался AА <150/90 мм рт.ст., и 94\% больных в этой поАгруппе $(n=176)$ Аостигли целевого значения $\mathrm{A} А$ в течение 6 месяцев терапии.

\section{Влияние терапии розувастатином на уровни липидов}

Изменение уровня общего холестерина и ХС АПНП после применения розувастатина показано на рисунке 4. По отношению к исхоАному значению, ко 2-му визиту уровни общего холестерина

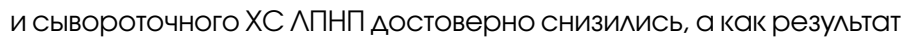
титрования Аозы степень этого снижения была наиболее выражена к 4-му визиту (6-й месяц). Уровень триглицериАов в сыворотке крови также Аостоверно снижался, а уровень ХС АПВП Аостоверно увеличивался в течение периода наблюАения $(p<0,05)$.

\section{Применяемые дозы розувастатина}

Распределение Аоз розувастатина, которые применялись в Аанном исследовании (10 мг, 20 мг), показаны на рисунке 5.

\section{Эффективность терапии розувастатином}

Авторы рассматривали терапию розувастатином эффективной, если уровень сывороточного ХС АПНП бы^ ниже целевого значения Аля группы риска. Как слеАствие - титрования Аозы целевое значение <3,0 ммоль/^ было Аостигнуто у 59\% пациентов к 3-му визиту и у 67\% - к 4-му визиту (рис. 6). В ответ на 6-месячную терапию розувастатином Аоля пациентов, Аостигших целевого значения ХС $\wedge П Н П<2,5$ ммоль/^, составила 49\%, в то время как целевого значения <1,8 ммоль/^ Аостигли 40\% пациентов.

\section{Побочные эффекты}

В течение 6 месяцев исслеАования авторы наблюАали побочные эффекты, которые могут быть связаны с терапией, у 98 (4,5\%) из 2241 пациента, взятого на исследование. Большая часть, в общей сложности 148 побочных эффектов, были легкой интенсивности и в 4 случаях - умеренной интенсивности. События не требовали лечения в больнице. Большинство побочных эффектов составляли сухой кашель (3,1\%), отечность ног (2,2\%), боль в мыш-

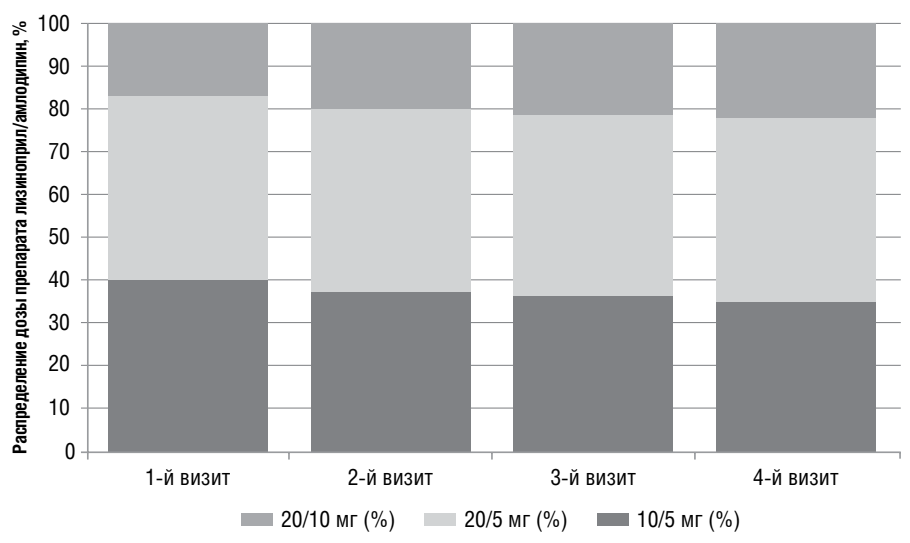

Рис. 2. Распределение дозы таблетированного препарата лизиноприл/ амлодипин

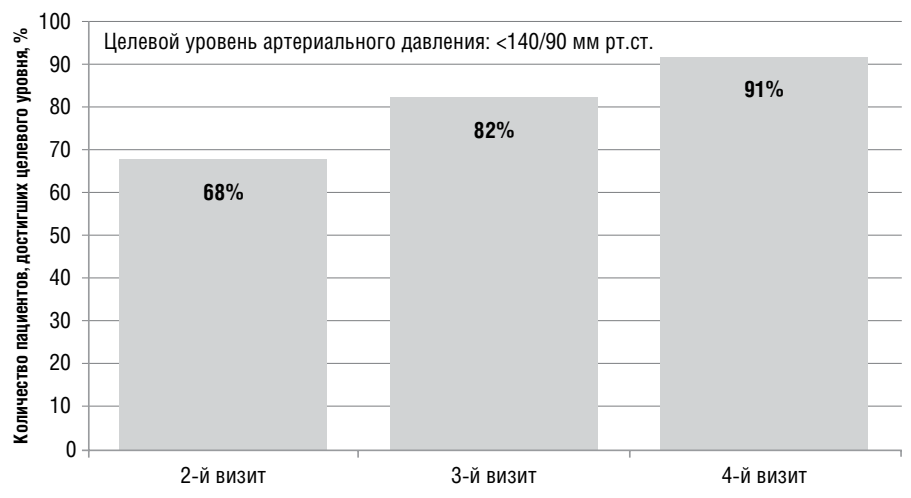

Рис. 3. Количество пациентов, достигших целевого уровня артериального давления
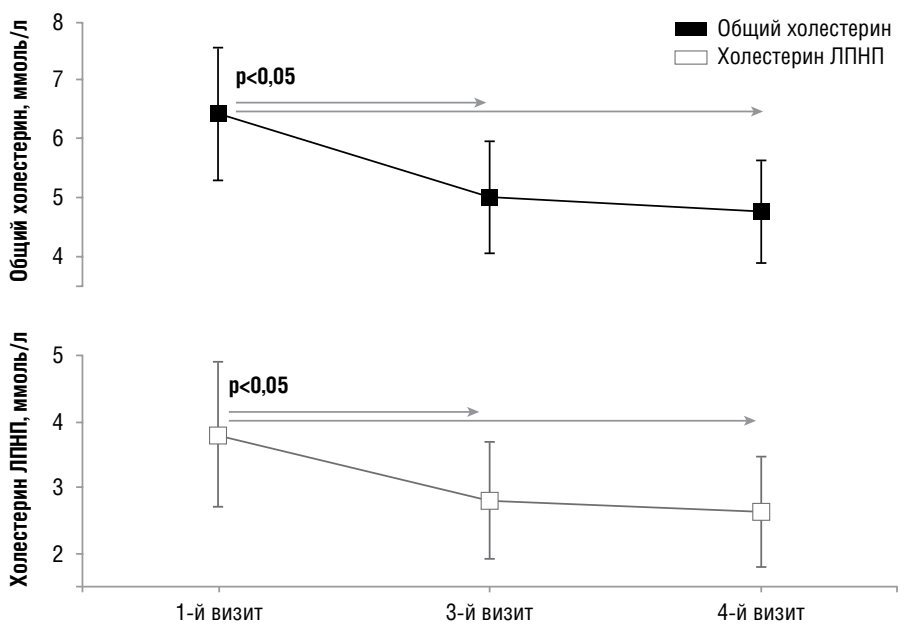

Рис. 4. Изменение общего холестерина и холестерина ЛПНП после применения розувастатина 


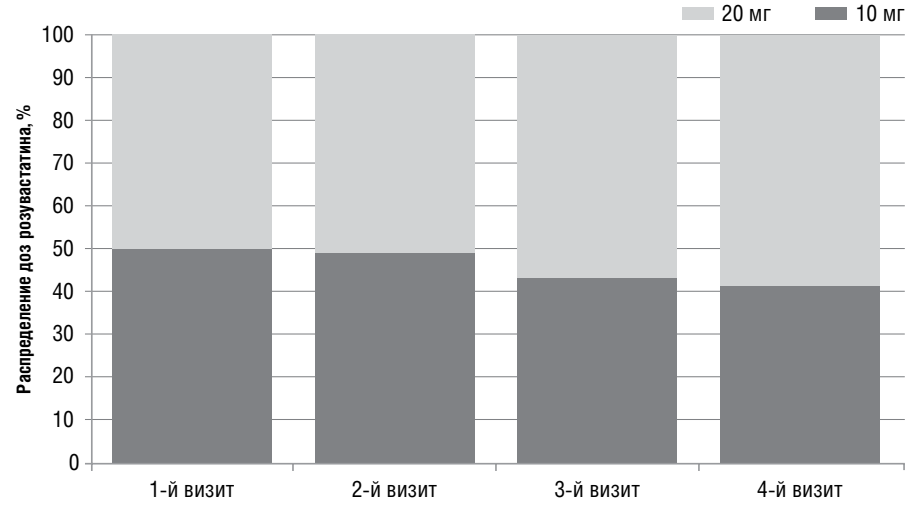

Рис. 5. Распределение доз розувастатина

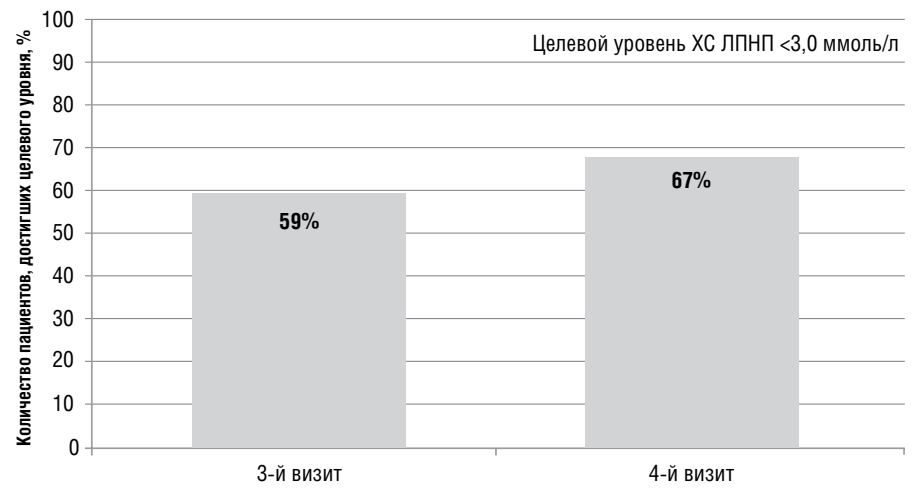

Рис. 6. Количество пациентов, достигших целевого уровня холестерина ЛПНП

цах (1,1\%), головокружение (0,2\%). ^изинопри^/ам^одипин терапия была приостановлена в общей сложности в 9 случаях и розувастатин терапия - в 10 случаях. Причины этого были неявка на контрольный визит - в 2 случаях, сухой кашель (5 случаев), отечность ног (2) и боль в мышцах (2).

\section{Резюме}

В Аанном клиническом исслеАовании авторы проанализировали эффективность и безопасность антигипертензивной лекарственной терапии комбинацией мизиноприл/ам^оАипин с фиксированной АОзой и холестерин-снижающего препарата розувастатина в свобоАной лекарственной форме при комбинированной терапии у пациентов с артериальной гипертензией и сопутствующей гиперхолестеринемии с высоким и очень высоким кардиоваскулярным риском. Пациенты, которые получали ранее гипотензивную терапию, реагировали аналогично пациентам, не получавшим ее Аля снижения артериального Аавления.

В Аанном исслеАовании непрерывное использование розувастатина значительно снижало уровень холестерина АПНП: при 6-месячной терапии 67\% пациентов Аостигли целевого значения ниже 3,0 ммоль/^.

На основании результатов Аанного кАинического исслеАОвания И АитературНЫХ Аанных МОЖНО САЕАать ВЫВОА О ТОМ, Что ГИПОтензивная лекарственная терапия комбинацией лизиноприл/ ам^оАипин с фиксированной АОзой в сочетании с розувастатином может эффективно и безопасно использоваться у пациентов с артериальной гипертензией легкой или умеренная степени и сопутствующей гиперхолестеринемией с высоким и очень высоким карАиоваскулярным риском.

Аодаткова інформація. Автори заявляють про віАсутність конфлікту інтересів.

Статья аАаптирована изАательством «МеАикс групп» по материалам, предоставленным компанией Рихтер ГеАеон. Оригинал впервые опубликован в журнале Cardiologia Hungarica 2015

\section{Список использованной литературы}

1. WHO Library Cataloguing-in-Publication Data, World health statistics. - ISBN 978 924 156359, 2008.

2. Kiss I. A hypertoniabetegség felnõttkori és gyermekkori kezelésének szakmai és szervezeti irányelvei [Professional and organisational guidelines for the adult and paediatric treatment of hypertension disease]. Position statement and protocol of the Hungarian Society of Hypertension // Hypertonia és Nephrologia [Hypertension and Nephrology]. - 2008. - Vol. 12 (S2). - P. 85-156.

3. Tedesco M.A. et al. Effects of monotherapy and combination therapy on blood pressure control and target organ damage: a randomized prospective intervention study in a large population of hypertensive patients // J. Clin. Hypertens. - 2006. - Vol. 8. - P. 634-641.

4. Okin R.M. et al. Regression of electrocardiographic left ventricular hypertrophy during antihypertensive treatment and the prediction of major cardiovascular events // JAMA. - 2004. - Vol. 292. - P. 2324-2349.

5. Scandinavian Simvastatin Survival Study Group: Randomised trial of cholesterol lowering in 4444 patients with coronary heart disease: the Scandinavian Simvastatin Survival Study (4S) // Lancet. - 1994. - Vol. 344. - P. 1383-1389.

6. Lipid Study Group: Prevention of cardiovascular events and death with pravastatin in patients with coronary heart disease and a broad range of initial cholesterol levels: the Long Trem Intervention with Pravastatin in Ischemic Disease (LIPID) study group // N. Engl. J. Med. - 1998. - Vol. 339. - P. 1349-1357.

7. Downs J.R., Clearfield M., Weis S. et al. Primary prevention of acute coronary events with lovastatin in men and women with average cholesterol levels: results of AFCAPS/TexCAPS. Air Force/Texas Coronary Atherosclerosis Prevention Study // JAMA. - 1998. - Vol. 279. - P. 1615-1622.

8. Baigent C., Keech A., Kearney P.M. et al. Cholesterol Treatment Trialist (CTT) Collaborators. Efficacy and safety of cholesterol-lowering treatment: prospective meta-analysis of data from 90,056 participants in 14 randomised trials of statins // Lancet. - 2005. - Vol. 366. - P. 1267-1278

9. Nissen S.E., Tuzcu E.M., Schoenhagen P. et al. REVERSAL Investigators. Effect of intensive compared with moderate lipidlowering therapy on progression of coronary atherosclerosis A randomized controlled trial // JAMA. - 2004. - Vol. 291. - P. 1071-1080.

10. Nissen S.E., Nicholls S.J., Sipahi I. et al. ASTEROID Investigators. Effect of very highintensity statin therapy on regression of coronary atherosclerosis: the ASTEROID trial // JAMA. - 2006. - Vol. 295. - P. 1556-1565.

11. Jones P.H., Davidson M.H., Stein E.A. et al. STELLAR Study Goup. Comparison of the efficacy and safety of rosuvastatin versus atorvastatin, simvastatin, and pravastatin across doses // Am. J. Cardiol. - 2003. - Vol. 92. - P. 152-160.

12. Schuster H., Barter P.J., Stender S. et al. Effects of switching statins on achievement of lipid goals: Measuring Effective Reductions in Cholesterol Using Rosuvastatin Therapy (MERCURY I) study // Am. Heart. J. - 2004. - Vol. 147. - P. 705-712. 